\title{
The Effect of Four Weeks of Vitamin C Supplementation on the Total Antioxidant Capacity and Serum Lactate of Women Active After Eccentric Exercise
}

\author{
Fatemeh Ahmadi ${ }^{1,2, *}$ \\ ${ }^{1}$ Master of Exercise Physiology, Payam Noor University, Hamadan, Iran \\ ${ }^{2} \mathrm{PhD}$ Student, University of Mohaghegh Ardabili, Ardabil, Iran \\ "Corresponding author: Fatemeh Ahmadi, Payam Noor University, Hamadan, Iran. Tel: +98-9188129733, E-mail: ffatemehahmadii@gmail.com
}

Received 2016 September 30; Revised 2016 November 07; Accepted 2016 December 13.

\begin{abstract}
This study aimed to determine the effects of 4 weeks of vitamin C supplementation on total antioxidant capacity and serum lactate of women active after eccentric exercise. Twenty active and healthy female volunteers $(23 \pm 1.4$ years, the percentage of fat $21.49 \pm$ 1.62 and the maximum oxygen consumption of $45.26 \pm 2.18 \mathrm{~mL} / \mathrm{kg}$. min) were divided into 2 random groups of complementary homogenized vitamin C (1000 mg daily) and placebo (lactose $1000 \mathrm{mg}$ ). After 4 weeks of supplementation, all subjects participated in an aerobic exercise on a treadmill at 80\% of maximal oxygen consumption (negative slope of 5 degrees) for a total of 45 minutes. Initial blood sample were taken at baseline before starting supplementation, the 2nd blood sample was taken after completing the supplementation, and the 3rd sample was taken after the sports convention. The normal data was examined using repeated analysis of variance, Bonferroni and independent t-test at meaningful level of $5 \%$ by SPSS version 23 . The results showed that 4 weeks of acute consumption of vitamin $\mathrm{C}$, prior to exercise, significantly increased $(\mathrm{P}<0.05)$ the total antioxidant capacity of baseline. However, 45 minutes of running with a negative slope significantly decreased the total antioxidant capacity. Taking vitamin $\mathrm{C}$ had no effect on serum lactate of active women $(\mathrm{P}>0.05)$. According to the findings of the study, it can be concluded that vitamin $\mathrm{C}$ supplementation can probably reduce adverse changes in oxidative stress damage indices of aerobic exercise in disabled women by increasing total antioxidant capacity of the base serum.
\end{abstract}

Keywords: Vitamin C, Total Antioxidant Capacity, Lactate, Eccentric Exercise

\section{Background}

Today, researchers believe that regular participation in relatively strong aerobic activity can effectively enhance the health and aerobic capacity of athletes or even people with cardiovascular disease $(1,2)$. However, intense exercise results in oxidative stress (3). In muscles, the amount of oxygen consumption is much higher and reaches 100 to 200 times at the resting time. This leads to an increase in the electron flux (Efflux) in the mitochondria. Leakage of reactive oxygen species (ROS) from mitochondria during activity is the main source of oxidative stress (4). Other potential sources such as oxidation of purines, damage of iron-containing proteins, calcium homeostasis damage, and NADPH oxidase also increase the amount of ROS after exercise (4). On the other hand, one of the ways to deal with the adverse effects of oxidative stress caused by intense and heavy exercise is the use of antioxidant supplements and natural foods $(5,6)$. In this regard, we can mention the beneficial effects of vitamin $C$ as an antioxidant food $(7,8)$. Vitamin $\mathrm{C}$ directly reacts with superoxide and hydroxyl radicals. In addition, vitamin $\mathrm{C}$ converts vitamin $\mathrm{E}$ radical to vitamin E and oxidizes itself to toxic dehydroascorbate radicals (5).

Gomez-Cabrera and colleagues (2008) investigated the impact of $1000 \mathrm{mg}$ of vitamin $\mathrm{C}$ on endurance performance 3 times a week for 8 weeks. In this study, the participants exercised with $65 \%$ to $80 \%$ of maximum oxygen consumption as well as the results indicated that endurance capacity of the vitamin $\mathrm{C}$ group increased and in addition the increase of superoxide enzyme was prevented (9). In another study, Wadley and colleagues (2010) observed that taking 500 milligrams of vitamin $\mathrm{C}$ for 7 days in trained rats ( 60 minutes of running at a speed of $27 \mathrm{~m} / \mathrm{min}$ with 5 shelves) increased muscle mitochondrial and antioxidant enzyme in male mice (4).

Oberbach A and colleagues (2010) investigated the effect of taking $1000 \mathrm{mg}$ of vitamin $\mathrm{C}$ and 400 international units of vitamin E daily for 4 weeks and the participants had an acute exercise at the end. The results suggested that stress oxide increased in the supplementation group compared to the control group (10).

Given the controversies in the field of vitamin C supplementation and its products on oxidative stress induced 
by exercise, the question has still surfaced as to whether 4 weeks of acute vitamin $C$ supplementation by increasing antioxidant capacity can relatively decrease oxidative damages caused by activities of eccentric exercise and at least results in adverse effects of oxidative stress and its indicators? Therefore, this study aimed to determine the effects of vitamin C supplementation for 4 weeks on total antioxidant capacity and serum lactate of women active after eccentric exercise.

\section{Methods}

This study was conducted in the form of the quasiexperimental design (experimental and control), with repeated measurements (three-phase) as double blind. The population of the study included healthy active female students of Payam Noor University of Hamedan province (they had regular participation in activities, exercise, and avoided the use of any supplements and medications during the past 6 months). After distribution of cooperation announcements of the study among the students, 50 individuals volunteered to participate, where 20 candidates were qualified in the research project. The participants attended the coordination meeting and the researcher completely described the objectives and methods of measuring. By completing the informed consent form, the health questionnaires, and 24-hour dietary recalls, they underwent medical examinations. Volunteers did not use medicine and natural nutritional supplements due to illness or without prescription in the past month. Two weeks before the start of the study, firstly, the anthropometric indices, height, weight, and percentage of body fat were measured using a skin caliper thickness gauge (Skinfold Calipers) and three-point formula of American college of sports Medicine (triceps skin folds of arm, abdominal above the right iliac). After determining the thickness of the skin pin, the mean of 3 measurements anywhere in the body was placed in the following formula.

$5.18845-(($ age $) * 0.15772)+2$ (A total of 3 parts) 0.00105

* $-($ A total of 3 parts $) *(0.39287)=$ Fat percentage

The maximum oxygen consumption was determined by the Bruce test on the treadmill (made in Italy with the Techno Jim mark) using the following formula:

$\mathrm{Vo}_{2 \max }(\mathrm{mL} / \mathrm{kg} / \mathrm{min})=14.76-(1.379 \times \mathrm{T})+\left(0.451 \times \mathrm{T}^{2}\right)-$ $\left(0.012 \times \mathrm{T}^{2}\right)$

Then, among 50 volunteers, 20 individuals with a mean age of $23 \pm 1.4$ years, the fat percentage of $21.49 \pm$ $1.69 \%$, and maximum oxygen consumption of $45.26 \pm 2.18$ $\mathrm{mL} / \mathrm{kg} / \mathrm{min}$ were chosen and randomly assigned to 2 equal groups of receiving vitamin C (1000 $\mathrm{mg}$ daily in the form of $500 \mathrm{mg}$ effervescent Tablets twice twice daily) and placebo
(11). Vitamin C, which was the product of Tehran's Osvah pharmaceutical company with license number 11/10103 was prepared. Moreover, in order to remind vitamin C during the research project, a 24-hour dietary questionnaire was used (12). Initial blood samples at baseline were taken before beginning supplementation from the antecubital vein of the right arm of all participants while they were fasting. The 2nd blood sample was taken upon the completion of 4 weeks of supplementation before the eccentric exercise. Then, all the participants respectively ran at a distance of 30-minute break after general heating using stretching and exercising movements on treadmill for 45 minutes in the form of 9,5-minute sets and with a 2-minute rest between each set. They ran with a negative slope of 5 and rested with 0 slopes with $80 \%$ of maximum oxygen consumption, and the 3rd blood samples were taken immediately after the sports convention (5).

\subsection{Sampling Method}

About $5 \mathrm{~mL}$ of blood was taken each time in vials without anticoagulant for preparing serum and determining blood indicators such as the total antioxidant capacity (TAC) and lactate. All measurements were performed under identical conditions. In addition, 48 hours before the test, the participants avoided doing any heavy physical activity and their meal was similar before the test. Laboratory measurement methods: Serum total antioxidant capacity was measured using Randox kits with MX2332 number by auto analyzer (manufactured by American country) at a wavelength of $600 \mathrm{~nm}$. Serum lactate was measured using Randox kits with LC2389 number using auto analyzer (America).

\subsection{Statistical Method}

Firstly, the normality of the data (mean and standard deviation) was assessed using the Kolmogorov-Smirnov test. Then, changes of any of the indices were measured during different steps and were examined using repeated ANOVA and Bonferroni post hoc test. Differences between the groups were determined using the independent t-test. All statistical operations and analyses were conducted at the level of 5\% using SPSS statistical software version 23 .

\section{Results}

Table 1 shows the mean and standard deviation of individual characteristics (age, weight, height, body fat percentage, maximum oxygen consumption). Table 2 also shows the changes of indices at 3 stages of taking blood samples. 
Table 1. Mean and Standard Deviation of Physiological and Anthropometric Characteristics of the Participants

\begin{tabular}{lccccc}
\hline Groups & \multicolumn{3}{c}{ Indices } \\
\cline { 2 - 5 } & Age, $\mathbf{y}$ & Weight, Kg & Height, $\mathbf{m}$ & Fat Percentage & Maximum Oxygen Consumption, mmol/kg/min \\
\hline Vitamin C & $23.63 \pm 1.3$ & $65.12 \pm 4.51$ & $175.25 \pm 6.71$ & $21.3 \pm 7.4$ & $45.03 \pm 3.16$ \\
Placebo & $24.38 \pm 1.92$ & $62.75 \pm 5.25$ & $170.5 \pm 3.29$ & $20.6 \pm 4.29$ & $43.89 \pm 3.94$ \\
\hline
\end{tabular}

Table 2. The Mean and Standard Deviation of Indices in 2 Groups and Each Stage of Measurement

\begin{tabular}{|c|c|c|c|}
\hline \multirow[t]{2}{*}{ Indices } & \multicolumn{3}{|c|}{ Blood Stages } \\
\hline & Baseline & Stage Before Exercise & Stage After Exercise \\
\hline \multicolumn{4}{|c|}{ Serum total antioxidant capacity, $\mathrm{mmol} / \mathrm{L}$} \\
\hline Vitamin C & $1.96 \pm 0.08$ & $2.14 \pm 0.16^{\mathrm{a}}$ & $2.14 \pm 0.16^{\mathrm{b}, \mathrm{c}}$ \\
\hline Placebo & $1.51 \pm 0.31$ & $1.53 \pm 0.26$ & $2.18 \pm 0.13^{\mathrm{b}}$ \\
\hline Vitamin C & $0.19 \pm 0.85$ & $0.75 \pm 0.13$ & $2.53 \pm 0.93$ \\
\hline Placebo & $0.8 \pm 2.17$ & $0.79 \pm 0.26$ & $1.94 \pm 0.7$ \\
\hline
\end{tabular}

The results indicate that only the serum total antioxidant capacity of baseline significantly increased in the group receiving vitamin $\mathrm{C}$ after 4 weeks $(\mathrm{P}=0.001)$. However, changes of other variables were not significant $(\mathrm{P}=$ 0.001 ) (Table 2). Moreover, the reduction of the serum total antioxidant capacity of the vitamin $C$ group was significantly less than the placebo group after eccentric exercise $(\mathrm{P}=0.04)$. However, serum lactate (Table 2 ) was increasing in both groups.

\section{Discussion}

Four weeks of vitamin C supplementation significantly increased the total antioxidant capacity at baseline. In addition, vitamin $C$ could increase the capacity of antioxidant after exercise. The studies that are in line with the findings of this study include Oberbach $\mathrm{A}$ and colleagues (2010), Wadley and colleagues (2010), Walter and colleagues (2009), Ristow and colleagues (2009), Kang and colleagues (2009), Rosa and colleagues (2009), as well as Kabrya and colleagues $(2008)(3,4,9-11,13,14)$. Oberbach A and colleagues (2010) found that consuming 1,000 milligrams of vitamin C per day and 400 international units of vitamin E within 4 weeks increased antioxidant capacity and also avoided exercise-induced antioxidant capacity loss (10). The mechanism proposed in relation to the effects of vitamin C supplementation on total antioxidant capacity is in the way that vitamin $\mathrm{C}$ directly reacts with the superoxide hydroxyl radical. Moreover, it converts vitamin $\mathrm{E}$ radicals to vitamin $\mathrm{E}$, and it itself converts to toxic dehydroascorbate radical (8). The dominant antioxidant ascorbic acid is in plasma and eliminates free radicals in the plasma and prevents from their entry into the low density lipoprotein of blood $(12,15)$. On the other hand, Ali Reza Esteqamati and colleagues (2001) showed that taking vitamin $\mathrm{C}$ and $\mathrm{E}$ in people with diabetes had no significant effect on total antioxidant capacity. The severity of the impact of holding vitamin $\mathrm{C}$ in total antioxidant capacity is probably the severity of the disease of individuals in this study that reduces the total oxidative capacity in these patients (16). In a study on cardiovascular patients, Kang and colleagues (2009) found that taking 500 milligrams of vitamin C per day, compared to vitamin E (402 mg per day) as well as beta-carotene (20 milligrams per day), had the best performance in reducing oxidative stress (11). However, most research suggests that by increasing the antioxidant capacity, vitamin C prevents oxidative stress and associated complications such as inflammation (17).

According to the results of the study, 4-week supplementation of vitamin $\mathrm{C}$ had no significant effect on serum lactate. In other words, vitamin C had no effect to reduce the amount of lactate between pre and post-test. Karpos and colleagues (18) reported that taking vitamin E had no significant effect on the reduction of the produced lactate. Corby and colleagues (19) found that lactate has significantly increased in both male and female runners in both 
vitamin E and placebo groups.

\subsection{Conclusion}

The findings indicated that 4-week supplementation of vitamin $C$ prevents adverse changes of the indices of oxidative stress and inflammation after intense eccentric exercise by increasing the serum total antioxidant capacity at baseline. Thus, by taking precautions, athletes can be offered to use supplementation of vitamin $C$ in order to prevent loss of antioxidant capacity and oxidative stress of intense eccentric exercise-induced inflammatory effects.

\section{Footnote}

Conflict of Interests: Any conflict of interest by the authors is not expressed.

\section{References}

1. Edge J, Bishop D, Goodman C. The effects of training intensity on muscle buffer capacity in females. Eur J Appl Physiol. 2006;96(1):97-105. doi: 10.1007/s00421-005-0068-6. [PubMed: 16283370].

2. Helgerud J, Hoydal K, Wang E, Karlsen T, Berg P, Bjerkaas M, et al. Aerobic high-intensity intervals improve VO2max more than moderate training. Med Sci Sports Exerc. 2007;39(4):665-71. doi: 10.1249/mss.ob013e3180304570. [PubMed: 17414804].

3. Wray DW, Nishiyama SK, Monnet A, Wary C, Duteil SS, Carlier PG, et al. Antioxidants and aging: NMR-based evidence of improved skeletal muscle perfusion and energetics. Am J Physiol Heart Circ Physiol. 2009;297(5):H1870-5. doi: 10.1152/ajpheart.00709.2009. [PubMed: 19767527]

4. Wadley GD, McConell GK. High-dose antioxidant vitamin C sup plementation does not prevent acute exercise-induced increases in markers of skeletal muscle mitochondrial biogenesis in rats. J Appl Physiol (1985). 2010;108(6):1719-26. doi: 10.1152/japplphysiol.00127.2010. [PubMed: 20395544].

5. Sacheck JM, Milbury PE, Cannon JG, Roubenoff R, Blumberg JB. Effect of vitamin $\mathrm{E}$ and eccentric exercise on selected biomarkers of oxidative stress in young and elderly men. Free Radic Biol Med. 2003;34(12):1575-88. doi: 10.1016/S0891-5849(03)00187-4. [PubMed: 12788477].

6. Thompson D, Williams C, McGregor SJ, Nicholas CW, McArdle F, Jackson $\mathrm{MJ}$, et al. Prolonged vitamin $\mathrm{C}$ supplementation and recovery from demanding exercise. Int J Sport Nutr Exerc Metab. 2001;11(4):46681. [PubMed: 11915781].
7. Benzie IFF, Strain JJ. [2] Ferric reducing/antioxidant power assay: Direct measure of total antioxidant activity of biological fluids and modified version for simultaneous measurement of total antioxidant power and ascorbic acid concentration. 1999 ;299:15-27. doi: 10.1016/s0076-6879(99)99005-5.

8. Nikolaidis MG, Kerksick CM, Lamprecht M, McAnulty SR. Does vitamin $\mathrm{C}$ and $\mathrm{E}$ supplementation impair the favorable adaptations of regular exercise? Oxid Med Cell Longev. 2012;2012:707941. doi: 10.1155/2012/707941. [PubMed: 22928084].

9. Gomez-Cabrera MC, Domenech E, Romagnoli M, Arduini A, Borras C, Pallardo FV, et al. Oral administration of vitamin $\mathrm{C}$ decreases muscle mitochondrial biogenesis and hampers training-induced adaptations in endurance performance. Am J Clin Nutr. 2008;87(1):142-9. [PubMed: 18175748].

10. Oberbach A, Kirsch K, Lehmann S, Schlichting N, Fasshauer M, Zarse $\mathrm{K}$, et al. Serum vaspin concentrations are decreased after exercise-induced oxidative stress. Obes Facts. 2010;3(5):328-31. doi: 10.1159/000321637. [PubMed: 20975299].

11. Kang JH, Cook NR, Manson JE, Buring JE, Albert CM, Grodstein F. Vitamin E, vitamin C, beta carotene, and cognitive function among women with or at risk of cardiovascular disease: The Women's Antioxidant and Cardiovascular Study. Circulation. 2009;119(21):2772-80. doi: 10.1161/CIRCULATIONAHA.108.816900. [PubMed: 19451353].

12. Evans WJ. Vitamin E, vitamin C, and exercise. Am J Clin Nutr. 2000;72(2 Suppl):647S-52S. [PubMed:10919971]

13. Ristow M, Zarse K, Oberbach A, Kloting N, Birringer M, Kiehntopf M, et al. Antioxidants prevent health-promoting effects of physical exercise in humans. Proc Natl Acad Sci U S A. 2009;106(21):8665-70. doi 10.1073/pnas.0903485106. [PubMed: 19433800].

14. Rosa EF, Ribeiro RF, Pereira FM, Freymuller E, Aboulafia J, Nouailhetas VL. Vitamin C and E supplementation prevents mitochondrial damage of ileum myocytes caused by intense and exhaustive exercise training. J Appl Physiol (1985). 2009;107(5):1532-8. doi: 10.1152/japplphysiol.91166.2008. [PubMed: 19696358].

15. Coskun S, Gonul B, Guzel NA, Balabanli B. The effects of vitamin C supplementation on oxidative stress and antioxidant content in the brains of chronically exercised rats. Mol Cell Biochem. 2005;280(12):135-8. doi: 10.1007/s11010-005-8421-y. [PubMed: 16311914].

16. Estegamati A, Zaban A, Dosti. M. . Evaluation of antioxidant status and oxidative stress markers in patients with type II diabetes Melitos [In Persian].J Endocrin Metab. 2000;3(4):239.

17. Fisher-Wellman K, Bloomer RJ. Acute exercise and oxidative stress: a 30 year history. Dyn Med. 2009;8:1. doi: 10.1186/1476-5918-8-1. [PubMed: 19144121].

18. Kyparos A, Sotiriadou S, Mougios V, Cheva A, Barbanis S, Karkavelas G et al. Effect of 5-day vitamin E supplementation on muscle injury after downhill running in rats. Eur J Appl Physiol. 2011;111(10):2557-69. doi: 10.1007/s00421-011-1888-1. [PubMed: 21369732].

19. Cobley JN, Marrin K. Vitamin E supplementation does not alter physiological performance at fixed blood lactate concentrations in trained runners. J Sports Med Phys Fitness. 2012;52(1):63-70. [PubMed: 22327088]. 